\title{
LAS HISTORIAS QUE CONTAMOS
}

Fernanda Soto Joya $\mathbf{1}^{1}$

\author{
Y no dicen que esta revolución, \\ crecida en el castigo, \\ es lo que pudo ser y no lo que quiso ser.
}

(Galeano, 2008:305)

Ana es una gran contadora de cuentos. Cuenta cuentos de princesas y de príncipes que cruzan caños en la montaña y montan $\operatorname{cusucos}^{2}$ del tamaño de una bestia ${ }^{3}$. Habla de viejos sin dientes escondidos en cuevas oscuras, del sontín ${ }^{4}$ que te embruja y de la Virgen que te protege. Ella también habla de la guerra: "Qué triste, qué barbaridad fue eso...Parece sueño, pero fue verdad".

Ana es del municipio de Siuna, localizado en el Caribe Norte de Nicaragua. En esa región ni la insurrección popular de finales de los años 70 ni la represión somocista que le precedió se sintieron con la fuerza con la que llegó la Revolución Sandinista, inaugurada el 19 de Julio de 1979. La Revolución llevó a fuertes cambios en las formas de vida de la población rural y se presentó acompañada de una guerra que finalizó en 1990, pero que en esa región perduró en tono de "posguerra" hasta inicios del 2000. Esa guerra fue la "barbaridad" que Ana hubiera deseado fuese "sueño". Pesadilla puede ser otra palabra. Una guerra debe ser como una pesadilla. ¿Y una Revolución? ¿Puede ser también pesadilla?

Desde el 2006, cuando visité Siuna para entender qué significó la Revolución Sandinista para la población de esa región rural, me he preguntado cómo dialogamos con las varias memorias de la Revolución, en realidad, cómo dialogamos entre nosotras y nosotros sobre ese pasado. Me he preguntado también cómo la acción de narrar, oralmente o por escrito, incide en el "entendimiento", en el "dar sentido" al pasado para poder vivir en el presente. Cuando digo poder vivir lo digo literalmente, no con tono dramático sino

\footnotetext{
${ }^{1}$ Universidad Centroamericana (UCA), Nicarágua.

${ }^{2}$ Armadillos (Tatu)

${ }^{3}$ Forma popular en Nicaragua para llamar a las mulas.

${ }^{4}$ Obeah es una especie de ciencia oculta, para otros es magia... Entre la gente de habla española, el Obeah llegó a llamarse sontín (something) porque cuando el cliente consultaba con el Obeah man, después que este escuchaba el caso, le decía en inglés "I am going to give you something" (voy a darte algo). http://hillron.blogspot.com/2012/06/obeah-me-sontineame.html
} 
pragmático: ¿El narrar la memoria contribuye en la tarea de reconstituir los hilos subjetivos y los vínculos colectivos después de una guerra?

Más importante ha sido atisbar que las memorias de la Revolución que me narraron y las que yo misma narro van más allá de la Revolución. Ahí aparecen trozos de otras historias, memorias de desigualdades sociales que reflejan el clasismo, racismo y sexismo de nuestras sociedades. La propia Revolución Sandinista fue marcada por la tensa relación entre la intención de reconocimiento y quiebre de asimetrías sociales y la reafirmación y perpetuación de esas asimetrías. Al fin y al cabo, la Revolución deseó imponer una forma de ser, saber y poder que buscaba ser moderna y que resultó ser inevitablemente colonial ${ }^{5}$.

Finalmente, ¿se trata sólo de narrar el pasado? El hecho de narrar la memoria no garantiza que no se quedará inmóvil y si hay movimiento, este no garantiza que saldremos del mismo lugar, podemos girar siempre alrededor de un mismo eje de idealización o denigración de aquel pasado y de nosotros mismos ayer y hoy. El desafío es desestabilizar la memoria y desestabilizarnos como narradores; mover los ejes desde los cuales caminamos y entendemos.

Rivera Cusicanqui (2015: 21) llama a esas prácticas tareas libertadoras y considera que ellas deben acompañar el análisis del colonialismo interno que da forma a nuestras sociedades. En su obra esta autora ha propuesto la Sociología de la Imagen como un espacio, a través del trabajo con las imágenes, desde donde desfamiliarizar los supuestos académicos y problematizar el "colonialismo/elitismo inconsciente".

Para Rivera Cusicanqui (2015: 311), la Sociología de la imagen es además una práctica descolonizadora del conocimiento porque lleva a la/el investigador/a a "hacerte cargo de tu subjetividad y de tu proceso de conocimiento por medio de la percepción, la emoción, el hemisferio izquierdo subalternizado por nuestro entrenamiento racional”. En esta propuesta el pensar y el hacer no se separan. Y el hacer es auto-cuestionador, abierto,

\footnotetext{
${ }^{5}$ Los téminos: colonialidad del ser, saber y poder derivan de la obra de Aníbal Quijano. Ver Quijano, Aníbal. 2000. Colonialidad del poder y clasificación social. En Journal of World-Systems Research, VI, 2, Summer/Fall 200, 342-386. Special Issue: Festchrift for Immanuel Wallerstein. Sobre ejemplos de esa colonialidad en las zonas rurales es interesante el trabajo de Saldaña-Portillo, María Josefina. 2003. "Irresistible Seduction: Rural Subjectivity under Sandinista Agricultural Policy," in The Revolutionary Imagination in the Americas and the Age of Development. Durham: Duke University Press.
} 
creativo y respetuoso; un hacer que se distancia del seco y algunas veces prepotente “observar y analizar" y que procura más bien escuchar, sentir, valorar y respetar.

¿Pero, escuchar, sentir, valorar y respetar qué? Michael Taussig en History as Sorcery (1983), retoma las reflexiones de Walter Benjamin sobre la historia ${ }^{6}$ para analizar lo que él llama "conocimiento social implícito" y el papel de la historia y la memoria en su constitución. En su texto resalta la relevancia política que para Benjamin (1984: 88) tenía “el ámbito de lo imaginario, del mundo-sueño de la imaginación popular”. Ese espacio es precisamente dónde habita el conocimiento social implícito, "que mueve a las personas sin saber exactamente por qué, que hacelo real real y lo normal normal y sobre todo que lleva las distinciones éticas a ser políticamente poderosas" (Benjamin, 1984: 87). En muchos casos, la imaginación popular, el mundo-sueño, el espacio de lo imaginario, es desvalorizado o se asume debe ser "ordenado", como señala Taussig, sin reconocer la fuerza que tiene en los procesos colectivos.

Este conocimiento no es necesariamente políticamente contrahegemonico, por el contrario, Taussig (1984: 107) describe cómo la memoria que constituye y reproduce el conocimiento alrededor de la sanación mágica en el Putumayo ha estado al servicio de la colonización. Justamente, entender la fuerza de ese conocimiento nos ayuda a comprender cómo se articulan las constelaciones de poder que hacen "lo normal normal" y dan legitimidad a la desigualdad.

Un acercamiento respetuoso a las memorias de la revolución narradas por campesinas y campesinos, defensores o detractores de aquella gesta, nos ayuda a entender el conocimiento implícito que, a los ojos de muchos, hace comprensibles y hasta naturales tantas desigualdades. Nos ayuda además a entender cómo se establecen las relaciones sociales en esos espacios, cómo se articula lo real sin partir de supuesto de inferioridad que siempre han buscando "modernizar", "desarrollar", "hacer progresar" a los habitantes del campo o simplemente "al campo".

Esas memorias también contienen elementos desestabilizadores de lo "familiar" que contribuyen a repensar el pasado, el presente y el futuro. Una mirada sobre esas memorias que no las congela como "verdades" o "mentiras", que no busca "ordenar" el conocimiento del otro sino reflexionar sobre sus dimensiones e implicaciones en la vida de

\footnotetext{
6 "Las tesis sobre el concepto de historia".
} 
las personas, es una tarea libertadora. Más aún es el ubicarnos frente a estas narrativas dispuesto/as a cuestionar el "colonialismo/elitismo inconsciente" y, en esa tarea, "hacernos cargo de nuestra subjetividad, de nuestro conocimiento”, como señala Rivera Cusicanqui (2015), desde espacios más creativos.

En estas páginas propongo acercarnos a las memorias de Revolución desde una mirada respetuosa. Como verán las breves narrativas aquí presentadas son de habitantes de Siuna que apoyaron el proceso revolucionario. Nos muestran, por tanto, sólo un lado de aquella historia. Sin embargo, a pesar que quienes narran idealizan en muchos sentidos a la Revolución verán que sus memorias muchas veces desfamiliarizan lo "familiar" en las grandes narrativas Revolucionarias y entremezclan el ayer revolucionario con otras historias.

El texto esta organizado en cuatro partes. La primera parte es esta introducción. La segunda es el recuento histórico de los procesos vividos por la población de Siuna previo, durante y después de la Revolución Sandinista. Narro esa historia entremezclándola con la historia familiar de Anay de otros campesinos de la zona. La tercera parte del texto describe historias que Guillermo, quien trabajaba con Ana, me contó sobre la Revolución. Sus historias, como las de muchos otros, estaban envueltas en un halo religioso pero también estaban llenas de humor aun cuando contaba experiencias difíciles. Finalmente, esbozo una breve conclusión.

\section{Las historias de aquella tierra de oro}

En el 2006, cuando recopilé las narrativas que verán en este texto, Nicaragua vivía un año electoral. A finales de aquel año el Frente Sandinista de Liberación Nacional (FSLN) retornó al poder tras 17 años de gobiernos llamados neoliberales. Diez años después, en noviembre del 2016, el candidato del FSLN, Daniel Ortega, fue nuevamente electo para gobernar el país. Con tres reelecciones consecutivas, el FSLN ha mostrado ser la mayor fuerza política a nivel nacional. Esta fuerza, sin embargo, no ha estado libre de cuestionamientos que polarizan políticamente al país ${ }^{7}$. Una polarización que es de vieja

\footnotetext{
${ }^{7}$ Se cuestiona la centralización en la toma de decisiones dentro del gobierno. De igual manera se ha acusado al gobierno de realizar un fraude electoral en las elecciones del 2011 y del 2016. Ver "Una nueva carta en la
} 
data y que se sintió también con mucha fuerza durante la campaña electoral del 2006. En aquel momento los opositores del FSLN afirmaban que la victoria de este partido significaría la desdicha económica y social; sus seguidores, argumentaban lo contrario. Don Hilario, un viejo colaborador del FSLN en Siuna, me dijo en el 2006 que en el tiempo de la Revolución había habido "unas grandes maravillas", y esperaba que con una nueva victoria, otras maravillas se materializaran.

Era este el contexto en el que llegué a Siuna y luego a Mulukukú, un poblado $70 \mathrm{~km}$ al suroccidente de Siuna ${ }^{8}$. La región es una zona alejada de los centros de poder político del Pacífico y del Caribe, además de haber sido escenario de guerra durante los años 80. Teniendo como hilo conductor la historia de la familia de Ana, narraré aquíla historia de la gente que habita esta región y su experiencia con la Revolución Sandinista.

Ana nació en un caserío del municipio de Siuna en 1955. Su abuelo materno llegó desde Honduras buscando fortuna con el caucho y luego el cultivo de bananos. Su madre nació a lo orilla de un río, el río que su abuelo navegaba para transportar el banano hasta La Cruz del Río Grande, en lo que ahora es el Caribe Sur. Su abuelo paterno vino del norte de Nicaragua, junto a otros campesinos que llegaron a esa región movidos por el boom del oro en el poblado de Siuna a inicios del siglo veinte. El padre de Ana nació en aquellas tierras de oro y, como muchos, fue minero artesanal además de campesino.

Siuna era una zona poco poblada, con grandes extensiones de territorio aparentemente "sin dueños". Las comunidades indígenas que habitaban la zona no eran numerosas y prefirieron "apartarse" de los que llegaban, antes que enfrentarse a ellos (Jhon, 2015). Esos primeros campesinos que llegaron tomaron tierras, no las compraron. Cuenta Ana:

Era distinta la gente que llegó primero. Ellos agarraban la tierra que iban a usar, no más. Después de un tiempo se iban de ahí y agarraban otro pedazo de tierra para trabajar. Pero ya cuando mi papá vio que venía más y más gente buscando tierra, entonces él se fue a buscar un lugar bonito y lo carriló antes de que lo dejaran sin nada.

mesa de la OEA: el NO masivo del pueblo". Envío No 417, Noviembre 2016. http://www.envio.org.ni/articulo/5270

${ }^{8}$ Hasta el 2004 Mulukukú fue parte del municipio de Siuna. Posteriormente obtuve el rango de municipio. 
El padre de Ana cercó lo que sería su propiedad a finales de los años sesentas, cuando la modernización del agro impulsada por el Gobierno Somocista fomentó la industrialización agrícola y la concentración de tierra. Ante un posible incremento de tensiones sociales en el campo, la Alianza para el Progreso - iniciativa estadounidense para América Latina - de la mano del gobierno Somocista implementó en Nicaragua una reforma agraria basada en promover la migración y en la creación de asentamientos campesinos en zonas de la Costa Caribe ${ }^{9}$. Esa fue la política agraria de los Somoza, una dinastía familiar que concentró en sus manos el poder político, económico y social a lo largo de 45 años al frente y tras las bambalinas del poder, con la aprobación de los EUA.

Esta política agraria estaba anclada en una gran premisa: la existencia de grandes extensiones de tierra "libre" en el Centro-Caribe del país. Se decía entonces "lo que sobra en Nicaragua es tierra...¡Vayan, agarren tierra y trabájenla!” Esta fue una política heredera de las nociones de terra nullius de la colonia y se montó sobre los territorios de la población indígena y afro-descendiente de esas regiones de Nicaragua. No por casualidad lo miembros de esas comunidades llaman "españoles" a los campesinos mestizos que llegaban y aún llegan desde el pacífico y centro del país a sus territorios.

A mediados de los años 1970, con la creciente llegada de campesinos sin tierra a la zona, la tierra dejó de agarrarse y comenzó a venderse. La guerrilla del FSLN incursionó a finales de esa década. Lo hizo de forma tardía y con dificultades ya que la población de la región vivía en fincas alejadas unas de otras. La realidad de estos campesinos era diferente a la de los campesinos del pacífico. Varios tenían grandes extensiones de tierra, pero no tenían capital para ir más allá de la producción de subsistencia, tampoco habían fuerte centro de comercio, ni carreteras que facilitaran la comercialización.

Luis, hermano de Ana, colaboró con la guerrilla. En aquel entonces era muy joven, no llegaba a tener 18 años. Él cuenta que decidió apoyar a la Guerrilla para salvar a su papá. Lo relata así: "En ese tiempo la gente decía que los guerrilleros mataban a los jueces de mesta y yo quería salvar a mi papá, que era juez de mesta de la comunidad. Por eso me metí a la guerrilla”.

\footnotetext{
${ }^{9}$ Ver el trabajo de Matilde Mordt sobre Nueva Guinea en Sustento y sostenibilidad en la frontera agrícola: la evolución de la frontera en el sudeste de Nicaragua (2002).
} 
Los jueces de mesta eran figuras de autoridad rural ${ }^{10}$, ligados a la Guardia Nacional, el brazo armado del Gobierno de los Somoza. En algunos casos reproducían en las comunidades las prácticas represivas de la Guardia Nacional, en otros casos, principalmente en la comunidades rurales alejadas, eran más bien campesinos que sabían algunas letras y podían facilitar procesos de inscripción en las alcaldías locales. El padre de Luis y Ana se convirtió en juez de mesta de su comunidad por ser uno de los pocos hombres que sabía leer y escribir y porque además era delegado de la palabra ${ }^{11}$.

Luis no llegó a colaborar mucho tiempo con la guerrilla, a los pocos meses triunfó la Revolución. El 19 de Julio fue un hecho lejano para mucha gente en Siuna. Algunos pensaron que en sus vidas todo continuaría siendo igual porque siempre había sido así, pero todo cambió y mucho.

La madre de Ana, Doña Julia, me contó que el primer gran cambio fue la campaña de alfabetización. Ella recuerda con cariño a los alfabetizadores que llegaron a su comunidad, uno de ellos vivió en su casa. Me contó también que un año después los hombres de la comunidad, incluido su marido, por orientaciones del Gobierno formaron una Cooperativa donde compartían el crédito pero cada uno trabajaba individual. Ese mismo año, 1981, Luis se casó y también se cooperativizó aunque a los pocos meses lo reclutaron para ser parte de las Milicias Populares Sandinistas. En la zona ya se movían campesinos armados contrarios a la Revolución, muchos de ellos eran ex jueces de mesta o ex guardias que habían sido perseguidos en los primeros años por batallones Sandinista, se les llamó la contrarrevolución (los Contras). La respuesta del Gobierno Sandinista fue la creación de las Milicias y tres años después del Servicio militar obligatorio.

La política agraria del Gobierno Sandinista consideraba que las prácticas campesinas eran atrasadas. Su meta era modernizar el campo a través de proyectos rurales y cooperativas estatales $^{12}$. La mayoría de los campesinos de la zona no estaban de acuerdo

\footnotetext{
${ }^{10}$ Figuras políticas creadas en la Colonia. Fueron una suerte de policía rural que controlaba el trabajo forzado de las comunidades indígenas. En los años 30 la Guardia Nacional las empleó para afianzar su presencia en el campo.

${ }^{11}$ Los delegados de la palabra son miembros laicos de la iglesia católica que pueden celebrar encuentros religiosos.

${ }^{12}$ Ver: INRA. "Marco estratégico de la Reforma Agraria," (1981). Verónica Rueda Estrada. Recompas, Recontras, Revueltos y Armados: Posguerra y conflictos por la tierra en Nicaragua 1990-2008. (México: Instituto Mora: UNAM, Centro de Investigaciones sobre América Latina y el Caribe, 2015) and María Josefina, Saldaña-Portillo, "Irresistible Seduction: Rural Subjectivity under Sandinista Agricultural Policy," in
} 
con la cooperativización. La lógica de trabajo colectivo promovida por el Gobierno chocó con las concepciones locales de prosperidad basadas en la idea de trabajo individual y propiedad privada ${ }^{13}$. Tampoco estuvieron de acuerdo con el servicio militar obligatorio; muchos preferían irse por su voluntad a la Contra antes que ser obligados a cumplir el Servicio Militar. Ante todo esto no era extraño que campesinos como Don Cirilo, quién fue parte de la contra, dijera: "Aquí hubieron dos grandes fracasos: el primero fue cuando cerraron la mina y el segundo fue el 19 de Julio". La mayor parte de los campesinos de la zona pensaba como Don Cirilo.

Las tensiones en la zona fueron incrementando. En 1983 la presencia de la Contra en Siuna y otras zonas rurales se intensificó y llevó al gobierno a mover a la población a cooperativas grandes, cercanas a carreteras y poblados para ofrecer mayor protección y controlar mejor a la población. Las cooperativas de Siuna se convirtieron en Cooperativas de Defensa, ahí ya no se producía. El ejercito Sandinista lideró el desplazamiento de la población rural a estos nuevos espacios, exacerbando las fricciones que ya existían entre el gobierno y la población campesina.

La familia de Ana se negó a dejar su finca. En 1984 el padre de Ana murió, el corazón ya no le dio más vida. Doña Julia permaneció con sus cuatro hijos menores y Ana en el campo hasta 1986, cuando quedaron en medio de un combate entre el Ejército y la Contra. Fue entonces que Doña Julia tomó la decisión de moverse a una cooperativa; era ya casi imposible permanecer en el campo y su familia era blanco de la Contra por ser conocidos como Sandinistas. La decisión de dejar la tierra no fue fácil, Lupe, me contó:

\footnotetext{
Nosotros estuvimos un tiempo así [en la comunidad] porque el trabajo de uno, uno no lo quiere dejar. Yo recuerdo que eran cuarenta y cuatro casas en esa época en Sonate. Lo sé porque como profesor me tocaba hacer el censo. La gente comenzó a irse y al final sólo habíamos como cuatro familias. Y es que habíamos dejado la vida ahí con mi viejo. ¿Y uno para dónde se iba?
}

The Revolutionary Imagination in the Americas and the Age of Development. (Durham: Duke University Press, 2003), 109.

${ }^{13}$ Soto, Fernanda. Ventanas en la Memoria: Recuerdos de la Revolución en la Frontera Agrícola. Managua: UCA Publicaciones (2011). 
A finales del 1986 la mayor parte del municipio de Siuna quedó despoblado y las tierras abandonadas. Siuna era zona de guerra. Mientas los hombres adultos y jóvenes estaban combatiendo, las mujeres, niños y ancianos estaban en las cooperativas. Cuenta Anaque en la cooperativa donde ella vivió había escuadras de mujeres: "Ellas sembraban, limpiaban el potrero, y hacían un montón de cosas que normalmente hacen los hombre porque como ellos estaban movilizados. Ellas iban armadas a hacer esas cosas".

Ana tiene recuerdos triste de esa época, muchas otras mujeres también los tienen. Temerosas de la muerte de sus maridos, hijos, hermanos; sin poder sembrar por temor a ser atacadas; dependiendo del gobierno para poder alimentarse. Fueron tiempos de dolor para muchas. Los hombres por lo general recuerdan otras historias, algunos de guerra y heroísmo, aunque muchos concuerdan con Lupe, un profesor rural de la zona, quien me dijo: "Un solo infierno fue esa guerra".

Para 1989 los errores cometidos por el gobierno revolucionario, y principalmente los costos humanos de la guerra y del embargo comercial y económico decretado por el gobierno de Estados Unidos, habían minado la economía nacional y abatido el ánimo de la población. El 25 de febrero de 1990 la mayoría de los nicaragüenses votó en contra de la guerra y ese voto significó el final del gobierno del FSLN y de la Revolución Sandinista. Durante los años 90 los planes de ajuste estructural llevaron a la reducción de créditos rurales y asistencia técnica que aunado a la descapitalización causada por la guerra obligó a muchos a vender sus recién tituladas propiedades, iniciándose así la reconcentración de la tierra, la llamada contrarreforma agraria.

En esa década los bajos precios de los productos agrícolas acabaron de estrangular la ya débil economía campesina (Maldidier y Marchetti, 1996; Solá, 2008; Walker, 1997). A toda esta realidad se añadió la conflictiva y tardía pacificación en muchas zonas rurales del país ${ }^{14}$. El Estado se replegó nuevamente a las ciudades y la cooperación internacional asumió la implementación en el campo de programas económicos y sociales.

\footnotetext{
${ }^{14}$ Saldomando y Cuadra (1994) abordan a profundidad el tema en Los problemas de la pacificación en Nicaragua: recomposición de grupos armados y conflictos sociales. Para un análisis más profundo de estos procesos ver los estudios de Deena Abu-Lughod (2000), Failed Buyout: land rights for contra veterans in postwar Nicaragua, y de Salvador Martí i Puig (2002), El proceso de desmovilización y "reinserción" de la contra nicaragüense: algunas claves para el análisis de la violencia rural en Nicaragua.
} 
En los noventa el proceso migratorio que había caracterizado la vida en zonas como Siuna reinició con una intensidad preocupante. Los madereros se internaron en el territorio y la población que había emigrado a Honduras regresó a recuperar sus tierras. El retorno de la población que había abandonado la zona se produjo en un contexto de una enorme polarización política, con buena parte de la población todavía armada. Las diferencias políticas, los conflictos alrededor de las tierras y la difícil situación económica alimentaron la violencia que se sintió en la región durante toda la década de los años 90. Hasta inicios del año 2000 la zona estuvo plagada de ajustes de cuentas, robos, secuestros y asaltos.

Juan, quien estuvo buena parte de los años 80 en el ejercito y regresó a la cooperativa donde vivía su familia a finales de esa década me contó:

El 29 de Julio del 89, día de San Pedro, yo me fui del ejército y me vine a la cooperativa. Yo casi me muero en la guerra y hice un compromiso con Dios en la montaña, yo le dije "si me das vida, cuando llegue a la cooperativa me caso y me hago delegado de la palabra".

Y así lo hizo. Juan sobrevivió, regresó a la cooperativa, se casó y se hizo delegado de la palabra. A los pocos meses de su regreso se dieron las elecciones presidenciales y luego la desmovilización militar y el retorno de los miembros de la Contra. Me dijo:

En los 90 los socios de la cooperativa estábamos sin esperanza de organización. Hubo gente que se fue a sus tierras, los que todavía tenían sus tierras. Otros vendieron y compraron tierras más adelante. Se terminaron los préstamos, no venía más comida, la gente tuvo que meterle mecha a su propio zapato. La gente estaba desesperada. Había escaceses (sic) y robo entre la misma gente. Se dio una división de las tierras que fue otro gran problema porque entonces algunos vendieron y ahora lo tiene una gente rica. También comenzaron a sacar madera de los cerros.

Juan concluyó su relato diciéndome: “Antes nos queríamos. Hoy las cosas son más difíciles. Hoy hay una dificultad con todo". Ese antes se refiere a la época de la cooperativa, cuando la guerra unió a los comunitarios. 
Los hermanos de Ana, como muchos otros decidieron vender la tierra de la cooperativa e intentaron recuperar la propiedad de sus padres. Doña Julia vive con el menor de ellos. Ana decidió ingresar a la vida religiosa. Luis permaneció un tiempo más en la cooperativa y luego también vendió la propiedad. Hoy vive en Managua.

Yo conocí a Ana en el 2006. Viví junto a ella y sus hermanas religiosas en un Centro educativo (El Centro) que crearon en el poblado de Mulukukú. Con ella y sus hermanas compartí mucho. Recuerdo que a finales de ese año nuestras conversaciones giraban alrededor de las elecciones de aquel año. La campaña electoral del partido opositoral FSLN (el Partido Liberal) centraba sus mensajes en la descripción de historias de finqueros y campesinos asesinados o encarcelados por el ejército Sandinista. Todos los fines de tarde escuchábamos a aquellos hombres culpando a los sandinistas por haber cometido incontables asesinatos.

La guerra estaba a flor de piel y el ayer parecía regresar con los mismos colores de entonces. En las calles la gente comentaba: "Si gana el FSLN vuelve la guerra", "Se nos van a llevar a los chavalos", "Los sandinistas son unos asesinos". Un día de tantos, en medio de la cena y los gritos del locutor de la Radio liberal, Ana no consiguió contenerse más:

¡Ideay!, si la guerra no la hizo sólo el Frente. Si ellos también mataron, ellos también estuvieron ahí haciendo cosas horribles. Con el Sandinismo pasa como con la Iglesia: por los errores de unos pocos lo pagamos todos y nos rechazan. La guerra sucedió, eso es cierto, pero no porque los sandinista quisieran. Y además, es cierto que algunos campesinos por ignorancia pudieron hacer cosas malas, pero los ricos las hacen igual, pero con conocimiento.

Ana podía contar el otro lado de la historia: las cooperativas quemadas por la Contra, los campesinos sandinistas asesinados, los secuestros, las violaciones a las mujeres, los campos minados. Ella señalaba también lo que nicaragüenses, sandinistas o no sandinistas, aprenden desde siempre: la sociedad nicaragüense se divide entre nosotros los pobres - y ellos, los ricos. 


\section{“¿Viva Sandino!”}

Aquel día llegué tarde a Mulukukú. El bus venía lleno y avanzaba lentamente. Dos meses antes había terminado el invierno y la carretera de Río Blanco en adelante estaba llena de hoyos. Encontré la casa de las Hermanas cerrada - habían ido a un rezo - y hallé a Guillermo y a un vecino en el ranchito, por la cocina. Escuché el viejo radio de Guillermo. Tenía sintonizada Radio Ya, una radio sandinista. Se me había olvidado que era 21 de febrero, día en que en 1934 asesinaron a Sandino ${ }^{15}$. Un mes antes, Daniel Ortega había tomado posesión del gobierno. Su discurso, haciendo memoria del "padre" del Sandinismo, era un acto presidencial. Me senté con ellos a escuchar el discurso. Estábamos los tres serios y concentrados, con la mirada puesta en el radio, cuando Ortega hizo referencia a "los gringos ${ }^{16}$ imperialistas”. Guillermo sonrió y dijo: “¡Daniel es el único que se les para a los gringos, ellos tienen miedo de lo que él dice!".

Horas después, mientras intentaba dormir, me acordé de un viaje frustrado a Honduras unos meses después del huracán Mitch, en 1999. Venía con nosotros un amigo de la secundaria. Íbamos por Ocotal, cerca de la frontera con Honduras, cuando nos encontramos con el ejército gringo repartiendo alimentos a la población damnificada. Mi amigo dijo: "Estos jodidos ya se vienen a meter aquí de nuevo, pero están en Las Segovias, la tierra de Sandino". Después recordé a un alemán que me contó que cuando el FSLN ganó las elecciones en noviembre de 2006, lo primero que hicieron los chavalos del barrio granadino donde vivía fue ir su a casa a gritarle: “¡Ahora vas a ver, gringo hijueputa!”. Le enojó que lo confundieran con gringo.

Esa noche dormí con los gringos imperialistas en la cabeza y desayuné con Sandino porque en la mañana, mientras enrollaba la tortilla para comer mi primer bocado de frijoles, se apareció Ramón, un joven que trabajaba en El Centro, indignado. "Mire, hermana, yo no entiendo: ¿Para qué gritan los sandinistas ¡Viva Sandino! si ya está muerto?" Guillermo, que estaba allí, le contestó: "Porque sus ideas viven. Es lo mismo que

\footnotetext{
${ }^{15}$ Augusto Cesar Sandino lideró la resistencia nicaragüense en contra de la ocupación estadounidense a inicios del siglo XX en Nicaragua. Décadas más tarde su lucha de guerrilla, sus convicciones anti imperialistas y sus ideales sociales fueron retomados por miembros del Frente Sandinista de Revolución Nacional (FSLN).

${ }^{16}$ En Nicaragua se le llama gringos a las personas de los EUA. Muchos llaman gringos a cualquier personas blanca y de cabello rubio, caracteristican que asocian con ser de EUA.
} 
cuando decimos ¡Viva Cristo! A Cristo lo mandaron a matar porque sus ideas eran por los pobres, igual a Sandino". Con la impaciencia de sus 18 años, Ramón hizo un gesto con la cabeza y se fue al fogón a servirse café. En el aire quedó un silencio raro que duró los pocos minutos que nos tomó encontrar otro tema de conversación y continuar desayunando.

Guillermo no habla casi nunca de política. Lo que le gusta es contar historias de juventud. Entonces aparece la guerra y acompaña el relato con gestos, imitando los ruidos de las bombas y de las balas que pasaban silbando sobre su cabeza. Describe los lugares en donde estuvo, los ríos que cruzó y en sus historias reaparecen, sin que él lo diga con palabras, los muertos que cargó y que aún carga.

Guillermo me acompañó a las comarcas del municipio. Cuando yo entrevistaba a la gente miraba para otro lado y hacía como que estaba pensando en otra cosa. Se reía quedito ${ }^{17}$ con mis torpezas y en el camino de regreso por las veredas me explicaba por qué otros también se habían reído de mí. Una vez le pregunté: “¿Guillermo, por qué usted opina por los sandinistas?":

Porque ése fue el primer partido por el que voté. Mire, es que antes uno no opinaba, lo llamaban a que fuera a votar y antes de marcar cualquier cosa le decían por quién tenía que votar y le daban su nacatamal ${ }^{18}$. Así era en la época de Somoza. Pero con el FSLN no fue así. Además, del Frente surgió la democracia, porque teníamos las armas en la mano y podíamos decir que no había elección, pero no hicimos eso.

A Guillermo como a Ana también le gusta contar historias, pero las suyas son diferentes. "En la cooperativa -me contó- hubo una mala cosecha y una buena cosecha y después ya no supe más porque me fui movilizado”. “YY usted nunca pensó en irse con la Contra?", le pregunté. Me dijo lo que ningún hombre sandinista que había conocido se hubiera atrevido a decirme: "Sí, sólo una vez pensé irme con ellos. Fue cuando me metió preso la policía”.

Estaba yo en Puerto Cabezas, andaba sin cédula ${ }^{19}$ y de civil, estaba regresando de la comunidad. La policía andaba agarrando a los hombres en el camino y pidiéndoles la cédula, al que no tenía cédula se lo llevaban preso. Como yo no la andaba me llevaron. Llegando a la comisaría nos pusieron en fila y nos iban pasando individual a un cuarto. Yo escuchaba que a los que entraban les pegaban, se oían los golpes y a mí se me

\footnotetext{
${ }^{17}$ Silenciosamente

${ }^{18}$ Comida típica hecha con masa de maíz y envuelta en hojas de plátano.

19 Tarjeta de identidad
} 
chiriciaba ${ }^{20}$ el pelo sólo de pensar que me iban a hacer eso. Yo dije en mis adentros 'No, a mí no me hacen eso'. Entonces cuando llegó mi vez ni esperé para que me llevaran y de un solo golpe bajé al policía, que se fue directo al suelo. Después me arremangué la camisa, esperando que el resto se me tirara encima pero no hicieron nada. Levantaron al hombre y se metieron al cuarto. Al rato salieron y les dijeron a los otros que se fueran y a mí me dejaron preso una semana, de castigo. Hasta después de una semana me reporté en el batallón.

Tan maleducada soy que siempre me río cuando Guillermo me cuenta esa historia. Me lo imagino como un súper héroe. A Guillermo no le molesta que yo me ría. Él también se ríe, especialmente cuando describe la cara de susto que tenían los policías cuando lo vieron con la camisa arremangada y con ganas de "bajárselos" a todos al suelo. Le pregunté por qué no andaba ese día la cédula y me dijo que, como venía de la comunidad, pensó que era mejor no llevar nada, por si la Contra lo agarraba en el camino.

A Guillermo no le gusta participar en cosas políticas ni andar dando opiniones, "porque la gente se disgusta por eso de la política". Pero como en el caso del "Viva Sandino", de vez en cuando expresaba su opinión, que era casi siempre favorable al Sandinismo y la Revolución. Para mí, lo aleccionador era que en general, cuando contaba historias de la Revolución narraba facetas que quienes la "defendían” obviaban o dejaban de lado.

Una de esas historias fue su regreso a su tierra. Cuando Guillermo le comunicó a su superior que quería salirse del ejército lo volvieron a echar preso. Estuvo en la cárcel un par de semanas hasta que confirmaron que no iba a unirse a la Contra. Le dieron permiso para regresar a su finca y al llegar encontró a otra familia en su tierra. Le dijeron que tenían un papel de la reforma agraria y que esa tierra se las había dado el gobierno. Guillermo, que también tenía un título, se fue a la oficina del MIDINRA ${ }^{21}$ en Siuna, buscó al director y le dijo:

Mire, en esa finca hay un hombre que dice que ustedes le dieron tierra ahí, ¿Y este título mío vale o no vale? 'Sí vale', me dijo el del ministerio y se voltea donde la secretaria y le dice 'Ahí sí metimos las patas' y ella le responde: 'Las habrá metido usted porque yo sólo hago lo que usted me dicta'.

\footnotetext{
${ }^{20}$ Tener los "pelos de punta"

${ }^{21}$ Ministerio de Desarrollo Agrario y Reforma Agraria
} 
Guillermo se rió un buen rato con esta historia. "Muchacha inteligente esa secretaria", me dijo. Guillermo regresó a su finca. Su esposa se había ido. Él comenzó a trabajar con la iglesia y estudió la secundaria. En su historia no había resentimiento ni con la policía, ni con el ejército ni con el gobierno. Muchos campesinos que vivieron lo mismo no lo pensaron dos veces y se fueron con la Contra.

\section{"Es que somos muy pobres"}

En el Centro los cursos de primaria se llamaban "intensivos" porque en cuatro meses se enseñaba lo que normalmente se aprende en un año. Las y los estudiantes eran en su mayoría adolescentes de comunidades rurales alejadas que por diferentes motivos no pudieron terminar la primera cuando eran niños. Después de dos encuentros, y si pasaban el examen, ellas y ellos iban al siguiente grado. Yo enseñé un año completo, dos encuentros, a las estudiantes mujeres cursando sexto grado. En el primer encuentro conocí a las muchachas, leímos cuentos, hicimos ejercicios físicos, hablamos sobre sus vidas y sobre sus planes a futuro.

Al inicio del segundo encuentro les pedí que me contaran por escrito lo que habían hecho en las "vacaciones". La mayoría relató que había hecho lo mismo de siempre: lavar, cocinar, cuidar a sus hermanos, cargar leña, buscar agua. María contó que pasó ayudando a su papá en la huerta de frijoles y que para la cosecha hizo un trato con él y su papá compartió con ella una pequeña parte de las ganancias con la venta de la cosecha. Reina estaba algo triste porque siempre hacía lo mismo en la finca. Creo que quería irse, pero no sabía todavía con quién. El relato de Alba llamó mi atención. Esto escribió:

En mi familia, a veces no me comprenden, dicen que lo que hago no es correcto. Yo deseara que mi familia fuera comprensiva conmigo.

A veces las pobrezas se apoderan de nosotros y no podemos salir adelante. Yo me pregunto por qué hay personas que no sufren nada, que lo tienen todo. ¿Será que ellos son más inteligentes? No sé.

Un hermano dice que estoy para nada en la casa, sólo haciendo gastar a mis papás. Yo a veces creo que tal vez mis papás le creen porque no me fueron a matricular este año. Yo les dije que iba a estudiar después de la promoción porque no quiero perder el año, como mis otras compañeras de clase que estudian y van a seguir estudiando, pero no me matricularon. A veces yo digo ¿qué será que no me entienden qué es lo que hablo? Y yo digo que es algo bueno para mí y para ellos también. Yo sólo pienso que ya no puedo forzarlos. Será la voluntad de Dios conmigo, será que hasta aquí voy a llegar. 
De todas las alumnas, Alba fue la única que habló de pobreza y se preguntó por la desigualdad. De todas, Alba fue la única que escribió sobre lo que otras sospechaban iba a ocurrir: ahí terminaban sus estudios. Como todas ellas, Alba habló de Dios y de su voluntad. Es probable que los papás de Alba no la matricularan porque no tenían dinero. El hermano de Alba quería que se fuera de la casa porque sería una boca menos que alimentar. Para entonces, Alba tenía 23 años y ya debería ser "responsabilidad" de un hombre y no de su familia. Cuando le preguntaba qué pensaba hacer en el futuro Alba me contaba que quería estudiar la secundaria para ser maestra en su comunidad. Yo intenté responder a la pregunta que hizo. Hablé de injusticias, y dije que esas no tenían nada que ver con "las inteligencias".

Una semana después leímos el único cuento que les gustó. Lo noté por la forma en que siguieron con los ojos cada una de las líneas del texto y por los comentarios después de leerlo. El cuento era de Juan Rulfo (1975) y se titula: “Es que somos muy pobres”. Narra la historia de una inundación, de una familia campesina, de un niño que recuerda la pérdida de la vaca que era la dote de su hermana y habla de su hermana, la Tacha:

Por eso le entra mortificación a mi papá, ahora por la Tacha, que no quiere vaya a resultar como sus otras dos hermanas, al sentir que se quedó muy pobre viendo la falta de su vaca, viendo que ya no va a tener con qué entretenerse mientras le da por crecer y pueda casarse con un hombre bueno, que la pueda querer para siempre. Y eso ahora va a estar difícil. Con la vaca era distinto, pues no hubiera faltado quien se hiciera el ánimo de casarse con ella, sólo por llevarse también aquella vaca tan bonita (Rulfo, 1975: 127).

Ese día hablamos sobre las pobrezas y sobre Dios, sobre dotes y casamientos. En Mulukukú una vaca vale más que una mujer. En el año 2007 hallaron enrollado en alambres de púas el cuerpo descompuesto de una adolescente flotando en un río cercano. Dijeron las Hermanas: "A una vaca nunca le harían eso".

Yo quisiera ser una narradora como Rulfo para contar con tanta sencillez y, a la vez, con tanta fuerza esas cosas que hacen la vida lo que es. Esas son las narrativas en movimiento, las imágenes que no se quedan quietas ni aquí, en el papel. Es también la forma en que se transmite el conocimiento implícito, lo que hizo que esa historia, de un 
autor de otro tiempo y de otro país, describiera algo tan cercano a las chavalas; un conocimiento que es "esencialmente inarticulado y simbólico, un conocimiento no discursivo de relacionalidad social" (Taussig, 1984: 87).

En este texto, procuré mostrar que la forma en que Ana respondía a la agresión del partido opuesto al Sandinismo y las memorias de Guillermo sobre la Revolución, también expresaron no solo "hechos" o "verdades" sino formas de sentir y de entender muchos otros elementos de su vida. Esas son memorias de Revolución que idealizan y a la vez nos muestran otra cara de aquel pasado y otras historias. La Revolución fue sueño y también pesadilla.

Descolonizar esas imágenes es colocarlas en movimiento, acercarnos a ellas y reconocer que la Revolución y nuestras narrativas sobre ella están marcadas por el elitismo inconsciente que menciona Rivera Cusicanqui, y por una memoria al servicio de la colonización, como diría Taussig. Y aquí no me refiero a acciones colonizadoras, aunque esas también están presentes, sino a la mirada colonial que se anida en nuestros corazones y nuestras razones. Eso que da legitimidad a tanta injusticia porque nos dicen que unos son "naturalmente" más que otros y merecen más.

Estoy convencida que es una tarea urgente entender el conocimiento social implicito al que se refiere Taussig (1984: 88), comprender el poder de la experiencia social, la fuerza “de lo imaginario, del mundo-sueño de la imaginación popular”, para desde ese espacio, que no es necesariamente contra hegemónico pero que es poderoso, entender este presente, la razón colonial, y rehacer nuestras historias nacionales e individuales, siempre haciéndonos cargo de nuestra subjetividad, reconociendo nuestra agencia. Sin embargo, aunque clamo por el reconocimiento de la agencia, sería injusto pensar que somos simplemente lo que deseamos ser. Por eso cito a Galeano al inicio de este texto. Al igual que la Revolución Cubana, la Revolución Sandinista fue lo que pudo ser y no lo que quiso ser y de eso es importante no olvidarnos.

Regreso a la historia de Alba y las jóvenes del Centro. ¿Por qué finalizar este texto con una narración que no es de Revolución? Porque en nombre del futuro de jóvenes como Alba se dijo se hacía aquella Revolución o se peleaba en su contra. Ver a esas chavalas, en el 2006, forjando oportunidades en contextos tan adversos siempre me inspiró. Ver su tenaz pelea por ser diferentes y a la vez iguales, esa forma de buscar otros marcos en sus vidas y a 
la vez regresar a viejas historias para poder entender el por qué de lo que vivían me confirmó la relevancia de las luchas sociales.

\section{Referencias}

ABU-LUGHOD, Deena. Failed Buyout: land rights for contra veterans in postwar Nicaragua. Latin American Perspectives, año 27, n⿳303, 2000, p. 32-62.

ENVÍO. Una nueva carta en la mesa de la OEA: el NO masivo del pueblo. En Envío, nº17, Noviembre, 2016.

GALEANO, Eduardo. Fidel. En Espejos:Una historia casi universal. Buenos Aires: Siglo XXI, 2008.

JHON, Eliberto. Presencia de colonos en el territorio MSBAS y las tensiones sobre la autonomía comunitaria de la tierra. Cuaderno de Investigación 51. Managua: Nitlapan, 2015.

MALDIDIER, Cristobal; MARCHETTI, Peter. El campesino-finquero y el potencial económico del campesinado nicaragüense. Managua: Nitlapan, 1996.

MARTÍ I PUIG, Salvador. El proceso de desmovilización y "reinserción" de la contra nicaragüense: algunas claves para el análisis de la violencia rural en Nicaragua. En Nuevos temas de seguridad en América Latina. Barcelona: Fundación CIDOB, 2002.

MIDINRA. Marco estratégico de la Reforma Agraria. Congreso Latinoamericano de Sociología. Managua: Departamento de Propaganda y Educación Política del FSLN, 1981.

MORDT, Matilde. Sustento y sostenibilidad en la frontera agrícola: la evolución de la frontera en el sudeste de Nicaragua.Managua: Imprimatur Artes Gráficas, 2002.

QUIJANO, Aníbal. Colonialidad del poder y clasificación social. En Journal of World-Systems Research, año VI, n², Summer/Fall 2000, p 342-386.

RIVERA CUSICANQUI, Silvia. Sociología de la imagen: Miradas ch'ixi desde la historia andina. Colección Nociones Comunes. Buenos Aires: Tinta Limón, 2015.

RUEDA ESTRADA, Verónica. Recompas, Recontras, Revueltos y Armados: Posguerra y conflictos por la tierra en Nicaragua 1990-2008.México: Instituto Mora: UNAM, Centro de Investigaciones sobre América Latina y el Caribe, 2015.

RULFO, Juan. El llano en llamas. México: Fondo de Cultura Económica, 1975.

SALDAÑA-PORTILLO, Maria Josefina. The revolutionary imagination in the Americas and the age of development. Durham: Duke University Press, 2003.

SALDOMANDO, Angely; CUADRA, Elvira. Los problemas de la pacificación en Nicaragua: recomposición de grupos armados y conflictos sociales. Managua: Coordinadora Regional de Investigaciones Económicas y Sociales, 1994.

SOLÁ, Rosé. Estructura económica de Nicaragua y su contexto Centroamericano y mundial. Managua: Hispamer, 2008.

SOTO, Fernanda. Ventanas en la Memoria: Recuerdos de la Revolución en la Frontera Agrícola. Managua: UCA Publicaciones, 2011.

TAUSSIG, Michael. History as Sorcery. Representationsaño 7. Summer. 1984, p. 87: 109.

WALKER, T. William (ed.). Nicaragua without illusions: regime transition and structural adjustment in the 1990s. Wilmington, Del: SR Books, 1997. 